\title{
Nomenclatura de intervenções de enfermagem para clínica médica de um hospital escola
}

\author{
Nomenclature of nursing interventions to the medical clinic of a teaching hospital \\ Nomenclatura de intervenciones de enfermería para la clínica médica del hospital de enseñanza
}

\author{
Cláudia de Lourdes Henrieues de Lima', Maria Miriam Lima da Nóbrega" \\ 'Universidade Federal da Paraíba. Hospital Universitário Lauro Wanderley. João Pessoa, PB \\ "Universidade Federal da Paraíba. Departamento de Enfermagem em Saúde Pública e Psiquiatria. \\ Centro CIPE do Programa de Pós-Graduação em Enfermagem. João Pessoa, PB
}

Submissão: 10/09/2008

Aprovação: 24/07/2009

\section{RESUMO}

Estudo exploratório-descritivo desenvolvido com o objetivo de construir afirmativas de intervenções de enfermagem, tendo como base o Banco de Termos da Linguagem Especial de Enfermagem, a Nomenclatura de Diagnósticos de Enfermagem da Clínica Médica e o Modelo de Sete Eixos da CIPE ${ }^{\circledR}$. As afirmativas construídas foram submetidas a um processo de validação, considerando-se como validadas Quando alcançaram um índice de concordância $>0,80$, por enfermeiros Que atuam na referida clínica, e Que concordaram em participar do estudo. Espera-se que o uso desta nomenclatura, enQuanto instrumento tecnológico, permita o emprego do raciocínio clínico, a individualização da assistência e, conseQüentemente, impulsione os enfermeiros a Questionar e modificar sua atuação profissional na assistência, na gestão, no ensino e na pesQuisa.

Descritores: Enfermagem; Terminologia como assunto; Clínica Médica.

\section{ABSTRACT}

Descriptive-exploratory study developed with the aim of building affirmative nursing interventions based on the Bank of Language Special Terms of Nursing, the Nomenclature of Nursing Diagnostics of the Medical Clinic and the ICNP ${ }^{\circledR}$, Seven Axis Model. The affirmative built were subjected to a validation process, considering as validated when reaaching a $>0.80$ concordance index, by nurses who work in the referred clinic, and who agreed to participate. It is waited that the use of this nomenclature, while technological instrument, allow the employment of the clinical reasoning, attendance individualization and, consequently, stimulates the nurses to Question and to modify its professional performance in the assistance, the management, education and the research.

Descriptors: Nursing; Terminology as a topic; Internal medicine.

\section{RESUMEN}

Estudio exploratorio descriptivo, desarrollado con el objetivo de construir afirmativas las intervenciones de enfermería basada en el Banco de Términos del Lenguaje Especial de Enfermería, la Nomenclatura de Diagnósticos de Enfermería de la Clínica Medica y Modelo de Siete Ejes de CIPE ${ }^{\circledR}$. La afirmativa construido fueron sometidos a un proceso de validación, teniendo en cuenta como validado cuando el índice alcanzó un concordancia $>0,80$, de las enfermeras, Que actúan en la referida clínica, y Que de acuerdo a participar. Esperase Que el uso de dicha nomenclatura, mismos como un instrumento de tecnología, permita el empleo del raciocinio clínico, individualización de la asistencia, a consecuencia, estimulan a las enfermeras a la pregunta y modificar su desempeño profesional en la prestación de asistencia en la gestión, en la enseñanza y la investigación.

Descriptores: Enfermería; Terminología como asunto; Medicina interna.

*Artigo extraído da dissertação de Lima CLH. Construção de nomenclatura de intervenções de enfermagem para a Clínica Médica do HULW/UFPB [dissertação]. Ioão Pessoa: Centro de Ciências da Saúde, Universidade Federal da Paraíba; 2008.

Correspondência: Maria Miriam Lima da Nóbrega. Universidade Federal da Paraíba. Departamento de Enfermagem de Saúde Pública e Psieuiatria. Campus Universitário I. Cidade Universitária. CEP 58059-900. Joao Pessoa, PB. 


\section{INTRODUÇÃO}

A falta de um vocabulário comum ainda é um dos grandes obstáculos no desenvolvimento de sistemas clínicos na área de saúde no Que diz respeito à documentação do cuidado prestado Que possa servir de base para análise do custo e benefício deste cuidado e representação desta informação para a saúde da população. Além disso, deve atender a critérios como validade, especificidade, recuperação dos dados e facilidade de comunicação. Este vocabulário clínico deve ser simples de entender, fácil de codificar e intuitivo aos profissionais de saúde ${ }^{(1)}$.

O vocabulário da prática de enfermagem é documentado por meio do seu registro no prontuário dos pacientes, mas, segundo $\operatorname{Santos}^{(2)}$, as informações manuscritas não revelam Qualidade, não observam uma seeüência lógica, não objetivam a situação do paciente e não revelam o adequado procedimento nos cuidados para atender às necessidades de cada paciente. Além disso, as anotações são inconsistentes, ilegíveis e subjetivas, não havendo uma definição metodológica estruturada.

Entretanto, o registro clínico deve ser objetivo, claro e completo, de forma Que todos os membros da equipe de saúde com acesso a tais informações entendam o contexto e o significado das mesmas. É, por meio desse registro, Que se pode assegurar a execução e continuidade do tratamento adequado, viabiliza a equipe apropriada para prestar atendimento e ressalva aspectos éticos e legais ${ }^{(1)}$. Também, por meio dos registros, o enfermeiro trará a visibilidade para as ações cotidianas o Que, por vezes, acontece de forma fragmentada e oculta.

Para possibilitar a documentação dos cuidados de enfermagem, foram desenvolvidas diversas terminologias de enfermagem relacionadas com algumas fases do Processo de Enfermagem, como classificação de diagnósticos, intervenções e resultados de enfermagem, descritas a seguir. O Processo de Enfermagem é o principal recurso Que os enfermeiros possuem para registrar o seu trabalho e avaliar a Qualidade de suas atividades, aplicar e evidenciar seu conhecimento na assistência ao paciente e de consolidar sua prática profissional.

A Classificação Internacional para a Prática de Enfermagem CIPE ${ }^{\circledR}$ Versão 1.0 surge com um novo grupo de eixos Que unificou os dezesseis eixos das estruturas das Classificações de Fenômenos e de Ações da CIPE $^{\circledR}$ Versão Beta 2, consistindo numa única estrutura de classificação simplificada organizada em sete eixos, constituída de Ação, Cliente, Foco, Julgamento, Localização, Meios e Tempo. Essa nova estrutura soluciona, em ampla extensão, a redundância e ambigüidade de termos Que eram inerentes à CIPE ${ }^{\circledR}$ Versão Beta 2, proporcionando maior fundamento à classificação e serve de base para diversificar a expressão dos conceitos necessários em uma classificação internacional ${ }^{(3)}$.

As diretrizes da CIPE $^{\circledR}$ Versão 1.0 para criar afirmações de diagnósticos, resultados e intervenções de enfermagem foram desenvolvidas usando a norma ISO 18.104: Integração de um Modelo de Terminologia de Referência para Enfermagem ${ }^{(4)}$. O Modelo de Terminologia de Referência é constituído pelo modelo de diagnósticos de enfermagem e modelo de ações de enfermagem.

Para compor uma afirmação diagnóstica e resultado de enfermagem, é recomendado incluir obrigatoriamente um termo do eixo Foco e um do eixo Julgamento e incluir, também, outros eixos conforme a necessidade. Para compor afirmação de intervenção de enfermagem, é recomendado incluir, obrigatoriamente, um termo do eixo Ação e um do eixo Foco e incluir outros eixos conforme a necessidade. Estas afirmações podem ser organizadas em grupos significativos para a prática de enfermagem e para Catálogos CIPE ${ }^{\circledR}$ Que, nesta pesquisa, é denominada de nomenclatura.

Este estudo teve como objetivo construir as afirmativas de intervenções de enfermagem tendo como base o Banco de Termos da Linguagem Especial de Enfermagem da Clínica Médica do HULW/ UFPB, o Modelo de Sete Eixos da CIPE ${ }^{\circledR}$ Versão 1.0 e a Nomenclatura de Diagnósticos de Enfermagem desta Clínica; e validar as intervenções de enfermagem da Nomenclatura desenvolvida para a Clínica Médica com participação de enfermeiros, assistenciais e docentes, Que atuam na referida clínica.

\section{MÉTODO}

A abordagem metodológica utilizada para o desenvolvimento desse estudo foi uma pesquisa exploratório-descritiva. Antecedendo sua execução, o projeto foi submetido à apreciação do Comitê de Ética em Pesquisa, do Hospital Universitário Lauro Wanderley, da Universidade Federal da Paraíba, de acordo com o Que é preconizado na Resolução №. 196/96, do Conselho Nacional de Saúde Que regulamenta a pesquisa em seres humanos ${ }^{(5)}$, tendo recebido parecer favorável ao seu desenvolvimento, conforme protocolo № 004/07.

A pesquisa foi desenvolvida utilizando, como campo de estudo, a unidade da Clínica Médica do Hospital Universitário Lauro Wanderley, uma instituição autárouica federal e hospital-escola da Universidade Federal da Paraíba, Campus I, localizada na cidade de Ioão Pessoa - PB. Este hospital tem a finalidade de prestar assistência à saúde da comunidade, em todos os níveis e desenvolver atividades de ensino e pesquisa da graduação e pós-graduação das profissões da saúde e ciências afins. Representa uma estrutura de saúde de referência para o município de João Pessoa e polariza o atendimento a todos os demais municípios do estado da Paraíba.

Para a realização da construção da Nomenclatura de Intervenções de Enfermagem da Clínica Médica do HULW/UFPB, a partir dos termos inseridos no Banco de Termos da Linguagem Especial de Enfermagem da Clínica Médica do HULW/UFPB e da sua vinculação à Nomenclatura de Diagnósticos de Enfermagem da Clínica Médica do HULW/UFPB desenvolvida por Furtado ${ }^{(6)}$. Essa Nomenclatura possui uma lista de 41 diagnósticos de enfermagem possíveis de serem identificados nos clientes da Clínica Médica, os Quais foram organizados, de acordo com o referencial teórico da Sistematização da Assistência de Enfermagem do HULW/UFPB, Que utiliza a Teoria das Necessidades Humanas Básicas de Horta. Antes da sua utilização, as afirmativas diagnósticas foram validadas por enfermeiros assistenciais, docentes do DEMCA - CCS/UFPB que atuam na referida clínica e Que concordaram em participar do estudo.

Para o tratamento dos dados coletados os instrumentos foram numerados, e as variáveis, contidas nos mesmos, foram codificadas e inseridas em planilha do Excel for Windows para construção de uma base de dados. Os dados foram analisados, utilizando-se estatísticas descritivas. Consideraram-se as afirmativas de diagnósticos de enfermagem como validadas Quando alcançaram 
um Índice de Concordância $(\mathrm{IC})>$ ou $=0,80$ entre os participantes do estudo. As afirmativas diagnósticas validadas foram utilizadas para o desenvolvimento das intervenções de enfermagem.

Para a composição das afirmativas de intervenções de enfermagem, foram utilizadas as diretrizes do Conselho Internacional de Enfermagem (CIE) Que incluir, obrigatoriamente, um termo do eixo Ação e um termo do eixo Foco, incluir termos adicionais, conforme a necessidade, dos eixos Cliente, Localização, Meios e Tempo; o Banco de Termos da Linguagem Especial de Enfermagem da Clínica Médica do HULW/UFPB e as afirmativas diagnósticas validadas. Foi considerado também, nesse processo, o raciocínio terapêutico e a experiência das pesquisadoras na área.

Antes da inclusão das afirmativas de intervenções de enfermagem na Nomenclatura de Intervenções de Enfermagem da Clínica Médica do HULW/UFPB, as mesmas foram validadas por enfermeiros assistenciais e docentes do Departamento de Enfermagem Médico Cirúrgica e Administração (DEMCA/UFPB) Que atuam na referida clínica e que concordaram em participar do estudo.

Para o tratamento destes dados coletados, os instrumentos foram numerados, e as variáveis, contidas nos mesmos, foram codificadas e inseridas em planilha do Excel for Windows para construção de uma base de dados. Os dados foram analisados, utilizando-se estatísticas descritivas. Consideraram-se as afirmativas de intervenções de enfermagem como validadas Quando alcançaram um Índice de Concordância $(\mathrm{IC})>\mathrm{ou}=0,80$ entre os participantes do estudo.

\section{RESULTADOS E DISCUSSÃO}

Buscando o significado de Nomenclatura, encontra-se Que o mesmo pode ser um conjunto de termos peculiares a uma arte ou ciência, uma terminologia, uma lista, relação ou catálogo ${ }^{(7)}$. Para Pavel e Nolet ${ }^{(8)}$, nomenclatura é uma lista de termos, símbolos e fórmulas Que designam os nós de um diagrama conceitual, elaborada durante uma pesquisa temática. Neste estudo, utilizou-se o termo nomenclatura para designar o conjunto de afirmativas de intervenções de enfermagem Que foram desenvolvidas para os diagnósticos validados da Nomenclatura de Diagnósticos de Enfermagem da Clínica Médica do HULW/UFPB, desenvolvida por Furtado ${ }^{(6)}$.

$\mathrm{O} \mathrm{ClE}^{(3)}$ considera importante Que os enfermeiros possam lançar mão de listas de afirmações diagnósticas, resultados e intervenções de enfermagem, para facilitar a assistência de enfermagem e, conseqüentemente, a documentação dessa assistência. Considera também que o Modelo de Sete Eixos permite o desenvolvimento dessas afirmativas Que, Quando em conjunto, podem ser denominadas de catálogos $\mathrm{CIPE}^{\circledR}$.

Os catálogos CIPE ${ }^{\circledR}$ são definidos como subconjuntos de diagnósticos, intervenções e resultados de enfermagem para um grupo selecionado de cliente e prioridade de saúde, Que tem como propósitos tornar a $\mathrm{CIPE}^{\circledR}$ um instrumento útil Que pode ser integrado à prática de enfermagem no local do cuidado, ser usada para apoiar e melhorar a prática clínica, o processo de tomada de decisão, a pesquisa e as políticas de saúde ${ }^{(9)}$.

Para a etapa de construção da Nomenclatura de Intervenções de Enfermagem da Clínica Médica do HULW/UFPB, inicialmente foram validadas as afirmativas diagnósticas contidas na Nomenclatura de Diagnósticos de Enfermagem da Clínica Médica desenvolvida por Furtado ${ }^{(6)}$, com os enfermeiros assistenciais e docentes do
DEMCA/CCS/UFPB que atuam na referida clínica. Para isso, foi solicitada a colaboração dos participantes no sentido de apontar se as afirmativas diagnósticas são aplicáveis à Clínica Médica e se utilizam essas afirmativas em sua prática profissional.

Das 41 afirmativas diagnósticas, os enfermeiros consideraram aplicáveis à clínica médica 40 (98\%) com IC > 0,80 e apontaram Que utilizam na prática $22(53,7 \%)$ afirmativas Que obtiveram IC > 0,80 . Essas 22 afirmativas de diagnósticos de enfermagem foram utilizadas para a construção de intervenções de enfermagem, utilizando as diretrizes do $\mathrm{CIE}^{(9)}$, Que devem incluir, obrigatoriamente, um termo do eixo Ação e um termo do eixo Foco; incluir termos adicionais, conforme a necessidade, dos eixos Cliente, Localização, Meios e Tempo; o Banco de Termos da Linguagem Especial de Enfermagem da Clínica Médica do HULW/ UFPB e os termos do Modelo de Sete Eixos da CIPE ${ }^{\circledR}$ Versão I.0. Apesar da Quantidade de termos identificados na referida clínica, contidos no Banco de Termos, não foi possível construir todas as intervenções de enfermagem com base nesses termos; acredita-se Que este fato tenha acontecido devido à falta de registros dos enfermeiros em documentar a assistência do cuidado ao paciente. Foi levando também em consideração a literatura, uma vez Que o $\mathrm{CIE}^{(9)}$, para a construção de catálogos $\mathrm{CIPE}^{\circledR}$, recomenda Que possam ser adicionadas afirmativas identificadas na literatura da área e em resultados de pesQuisa Que forneçam evidências relevantes. Foi considerado, nesse processo, o raciocínio terapêutico na construção das intervenções e a experiência das peşuisadoras como enfermeiras assistenciais da referida clínica.

A Nomenclatura de Intervenções de Enfermagem foi organizada de acordo com os diagnósticos enunciados. Para cada diagnóstico de enfermagem, elegeram-se um mínimo de seis intervenções de enfermagem, resultando de uma lista de 3 I I intervenções de enfermagem, Que, nesta pesquisa, foi denominada de Nomenclatura de Intervenções de Enfermagem para a Clínica Médica do HULW/UFPB. Nessa Nomenclatura, as intervenções foram incluídas em ordem alfabética, cabendo ao enfermeiro, na sua utilização, a escolha das intervenções Que melhor se aplieuem ao estado de determinado paciente.

Antes da inclusão das afirmativas de intervenções de enfermagem na Nomenclatura de Intervenções de Enfermagem da Clínica Médica do HULW/UFPB, estas foram validadas por enfermeiros assistenciais e por docentes do DEMCA - CCS/UFPB que atuam na Clínica Médica, participando deste processo onze enfermeiros assistenciais e uma docente. Consideraram-se as afirmativas de intervenções de enfermagem como validadas Quando alcançaram um IC $>0,80$ entre os participantes do estudo.

Vale ressaltar Que nenhuma intervenção de enfermagem teve IC $>0,80 \mathrm{e}$, sim, foram apresentadas sugestões de retiradas ou acréscimos, por um ou dois enfermeiros, consideradas relevantes para o processo de inclusão e exclusão das intervenções.

O processo de validação das afirmativas de intervenções pelo grupo de enfermeiros resultou em 309 intervenções para os 22 diagnósticos de enfermagem validados, as Quais foram inseridas na Nomenclatura de Intervenções de Enfermagem da Clínica Médica do HULW/UFPB (Quadro I). As 309 intervenções de enfermagem deverão ser aprazadas, de acordo com o preconizado na literatura, com a rotina da clínica e com as especificidades de cada paciente, de maneira a garantir a operacionalização da prescrição em uma escala de tempo determinada. 


\begin{tabular}{|c|c|}
\hline \multicolumn{2}{|r|}{ NOMENCLATURA DE INTERVENÇÕESS DE ENFERMAGEM DA CLÍNICA MÉDICA DO HULW/UFPB } \\
\hline \multicolumn{2}{|r|}{ NECESSIDADES PSICOBIOLÓGICAS } \\
\hline$\overline{\mathrm{DE}}$ & Intervenção de Enfermagem \\
\hline 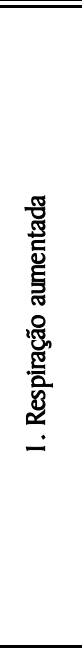 & $\begin{array}{ll}\text { I. } & \text { Administrar oxigenoterapia; } \\
\text { 2. } & \text { Aspirar cânula de traQueostomia; } \\
\text { 3. } & \text { Aspirar vias aéreas mediante ausculta pulmonar; } \\
\text { 4. } & \text { Auscultar sons respiratórios, observando presença de ruídos adventícios; } \\
\text { 5. } & \text { Avaliar os reflexos para a respiração adequada (tosse, vômito, deglutição); } \\
\text { 6. } & \text { Avaliar perfusão periférica; } \\
\text { 7. } & \text { Elevar cabeceira de cama; } \\
\text { 8. } & \text { Encorajar a tossir para remover secreções; } \\
\text { 9. } & \text { Estimular ingestão de líQuidos; } \\
\text { 10. } & \text { Estimular o paciente a mudar de posição corporal; } \\
\text { I1. } & \text { Estimular o reflexo da tosse; } \\
\text { 12. } & \text { Higienizar cânula e a subcânula de traQueostomia; } \\
\text { 13. } & \text { Monitorar capacidade do paciente para tossir efetivamente; } \\
\text { 14. } & \text { Monitorar secreções respiratórias; } \\
\text { 15. } & \text { Monitorar sinais vitais; } \\
\text { 16. } & \text { Mudar posição corporal; } \\
\text { 17. } & \text { Orientar para exercícios respiratórios; } \\
\text { 18. } & \text { Orientar repouso no leito; } \\
\text { 19. } & \text { Orientar sobre a maneira de tossir efetivamente. }\end{array}$ \\
\hline 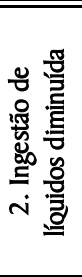 & $\begin{array}{ll}\text { 1. } & \text { Atentar para sinais de desidratação; } \\
\text { 2. } & \text { Avaliar as características da eliminação urinária; } \\
\text { 3. } & \text { Estimular ingestão de líQuidos; } \\
\text { 4. } & \text { Manter um registro da ingestão e da eliminação de líQuidos; } \\
\text { 5. } & \text { Monitorar a eliminação urinária; } \\
\text { 6. } & \text { Monitorar a perda de líQuidos (sangramento, vômito, diarréia, transpiração); } \\
\text { 7. } & \text { Oferecer líquidos a cada duas horas, Quando adeQuado; } \\
\text { 8. } & \text { Pesar o paciente diariamente }\end{array}$ \\
\hline 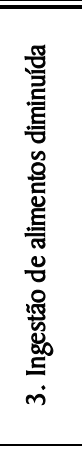 & 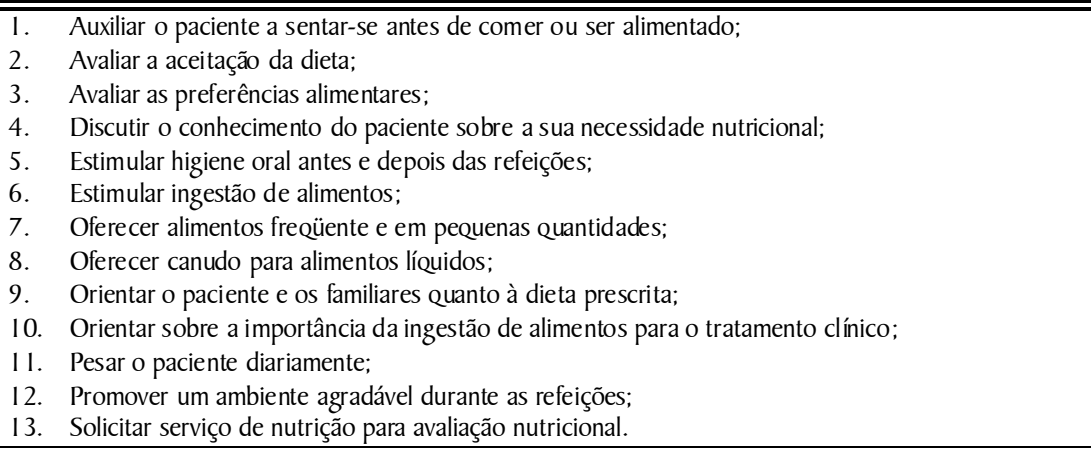 \\
\hline 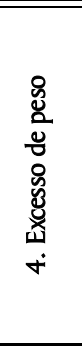 & $\begin{array}{l}\text { 1. Estimular à adesão a dieta alimentar; } \\
\text { 2. Estimular auto-estima; } \\
\text { 3. Incentivar reeducação alimentar; } \\
\text { 4. Oferecer reforço positivo dos hábitos de dieta adeQuados; } \\
\text { 5. Orientar a importância da dieta fracionada; } \\
\text { 6. Orientar mudança de hábitos alimentares; } \\
\text { 7. Orientar o paciente a mastigar bem os alimentos; } \\
\text { 8. Orientar o paciente e os familiares Quanto à dieta prescrita de restrição alimentar; } \\
\text { 9. Orientar sobre os riscos de saúde causados pelo excesso de peso; } \\
\text { 10. Pesar o paciente diariamente. }\end{array}$ \\
\hline 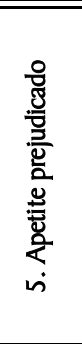 & $\begin{array}{l}\text { 1. } \\
\text { 2. Cuxiliar o paciente a se alimentar; } \\
\text { 3. Desenvolver uma relação de apoio com o paciente; } \\
\text { 4. Ensinar os conceitos de uma boa nutrição ao paciente; } \\
\text { 5. Estimular ingestão de alimentos; } \\
\text { 6. Identificar problemas relacionados com a alimentação; } \\
\text { 7. Orientar sobre a importância da dieta alimentar; } \\
\text { 8. Pesar o paciente diariamente; } \\
\text { 9. Proporcionar um ambiente agradável durante as refeições; } \\
\text { 10. }\end{array}$ \\
\hline
\end{tabular}

Quadro I. Nomenclatura de Intervenções de Enfermagem da Clínica Médica do HULW/UFPB. João Pessoa. 2007. 


\begin{tabular}{|c|c|}
\hline \multicolumn{2}{|r|}{ NECESSIDADES PSICOBIOLÓGICAS } \\
\hline $\mathrm{DE}$ & Intervenção de Enfermagem \\
\hline 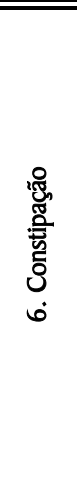 & $\begin{array}{l}\text { 1. Estabelecer horário para a eliminação intestinal; } \\
\text { 2. Estimular a deambulação; } \\
\text { 3. Estimular ingestão de líQuidos; } \\
\text { 4. Identificar os fatores Que possam contribuir para a constipação; } \\
\text { 5. Identificar hábito de eliminação; } \\
\text { 6. Informar o paciente sobre procedimentos de remoção manual de fezes, Quando necessário; } \\
\text { 7. Monitorar as eliminações intestinais, inclusive freeüência, consistência, formato, volume e cor; } \\
\text { 8. Monitorar ruídos hidroaéreos; } \\
\text { 9. Monitorar sinais e sintomas de constipação; } \\
\text { 10. Monitorar sinais e sintomas de impactação; } \\
\text { 11. Orientar o paciente/família sobre dieta com elevado teor de fibras; } \\
\text { 12. Proporcionar a movimentação ativa/passiva no leito; } \\
\text { 13. Remover a impactação fecal manualmente, se necessário; } \\
\text { 14. Solicitar serviço de nutrição. }\end{array}$ \\
\hline 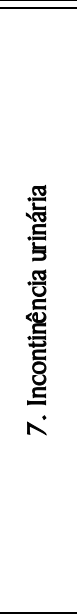 & $\begin{array}{l}\text { 1. Administrar pomada a cada troca de fralda; } \\
\text { 2. Auxiliar o paciente a desenvolver uma rotina de uso do sanitário; } \\
\text { 3. Desencorajar os líquidos após as } 19 \text { horas; } \\
\text { 4. Ensinar ao paciente os sinais e sintomas de infecção do trato urinário; } \\
\text { 5. Instalar dispositivo de incontinência; } \\
\text { 6. Limpar a área da pele dos genitais após eliminação urinária; } \\
\text { 7. Monitorar eliminação urinária, incluindo a freqüência, o odor, o volume e a cor; } \\
\text { 8. Monitorar padrão de eliminação; } \\
\text { 9. Orientar o paciente para monitorar os sinais e sintomas de infecção do trato urinário; } \\
\text { 10. Orientar o paciente/família a registrar o débito urinário; } \\
\text { 11. Promover integridade da pele; } \\
\text { 12. Promover integridade pessoal; } \\
\text { 13. Proporcionar higiene do paciente; } \\
\text { 14. Proporcionar motivação para aumentar o controle da bexiga; } \\
\text { 15. Providenciar papagaio ou aparadeira ao al cance do paciente; } \\
\text { 16. Trocar a roupa molhada; } \\
\text { 17. Trocar dispositivo de incontinência diariamente; } \\
\text { 18. Trocar fraldas. }\end{array}$ \\
\hline 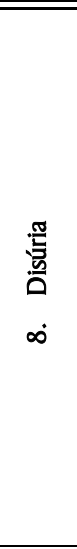 & $\begin{array}{l}\text { I. Avaliar a eficácia das medidas de controle da dor por meio de um levantamento constante da experiência de dor; } \\
\text { 2. Avaliar as características da eliminação urinária; } \\
\text { 3. Descrever as características da dor, incluindo o início, duração, freqüência, Qualidade, intensidade e os fatores } \\
\text { 4. Erecipitantes; } \\
\text { 5. Evimular ingestão de líquidos; } \\
\text { 6. Incentivar a micção freqüente a cada } 2 \text { a } 3 \text { horas; } \\
\text { 7. Incorporar a família na modalidade de alívio da dor, se possível; } \\
\text { 8. Manter um registro da ingestão e da eliminação de líQuidos; } \\
\text { 9. Monitorar a satisfação do paciente com o controle da dor, a intervalos específicos; } \\
\text { 10. Monitorar eliminação urinária; } \\
\text { I1. Monitorar resposta aos analgésicos; } \\
\text { 12. Monitorar sinais e sintomas de infecção; } \\
\text { 13. Oferecer informações sobre a dor, suas causas, tempo de duração, Quando apropriado; } \\
\text { 14. Orientar a esvaziar a bexiga por completo; } \\
\text { 15. Orientar Quanto à importância da higiene íntima após cada micção. }\end{array}$ \\
\hline 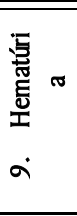 & 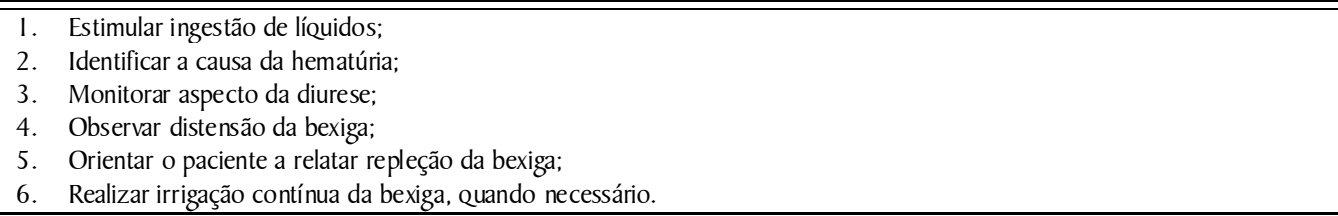 \\
\hline 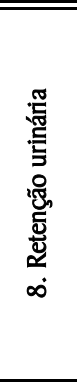 & $\begin{array}{ll}\text { I. } & \text { Auxiliar no uso do sanitário a intervalos regulares; } \\
\text { 2. } & \text { Estimular o reflexo de eliminação urinária; } \\
\text { 3. } & \text { Evitar deixar o paciente no vaso sanitário por mais de } 10 \text { minutos; } \\
\text { 4. } & \text { Inserir cateter urinário Quando necessário; } \\
\text { 5. } & \text { Instruir a comunicação de desconforto da bexiga ou incapacidade de urinar } \\
\text { 6. } & \text { Medir a eliminação urinária; } \\
\text { 7. } & \text { Monitorar a ingestão e eliminação de lícuidos; } \\
\text { 8. } & \text { Monitorar o grau de distensão da bexiga por meio da palpação e percussão; } \\
\text { 9. } & \text { Oferecer tempo suficiente para o esvaziamento da bexiga; } \\
\text { I0. } & \text { Proporcionar privacidade para a eliminação; } \\
\text { I1. } & \text { Usar o poder de sugestão com água corrente e descarga no vaso sanitário. }\end{array}$ \\
\hline
\end{tabular}




\begin{tabular}{|c|c|}
\hline \multicolumn{2}{|r|}{ NECESSIDADES PSICOBIOLÓGICAS } \\
\hline $\mathrm{DE}$ & Intervenção de Enfermagem \\
\hline 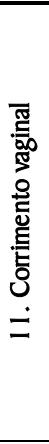 & $\begin{array}{l}\text { 1. Avaliar aspecto de secreções vaginais; } \\
\text { 2. Ensinar ao paciente hábitos de higiene; } \\
\text { 3. Ensinar a paciente e a família a forma de evitar infecções; } \\
\text { 4. Ensinar a paciente e família sinais e sintomas de infecção; } \\
\text { 5. Facilitar a higiene íntima após o término das eliminações; } \\
\text { 6. Instituir precauções de segurança com relação a roupa íntima e de cama da paciente; } \\
\text { 7. Investigar o tempo do aparecimento do corrimento; } \\
\text { 8. Limpar a área da pele dos genitais Quando necessário; } \\
\text { 9. Orientar a limpeza adeQuadamente do sanitário após cada uso da paciente; } \\
\text { 10. Orientar o uso de roupas íntimas de algodão; } \\
\text { I1. Orientar paciente/família a respeito da rotina de higiene íntima; } \\
\text { 12. Orientar sobre hábitos de higiene; } \\
\text { 13. Orientar uso correto da medicação prescrita. }\end{array}$ \\
\hline 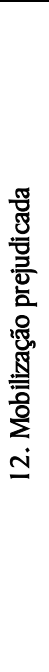 & $\begin{array}{l}\text { 1. Auxiliar no banho; } \\
\text { 2. Avaliar integridade da pele uma vez ao dia; } \\
\text { 3. Colocar os objetos de uso do paciente ao seu alcance; } \\
\text { 4. Dar banho no leito; } \\
\text { 5. Diminuir a fricção e o encostar de lençóis ao posicionar e virar o paciente; } \\
\text { 6. Elevar grades de cama; } \\
\text { 7. Encorajar o paciente a envolver-se nas mudanças de posição, Quando adeQuado; } \\
\text { 8. Evitar colocar o paciente em posição Que aumente a dor; } \\
\text { 9. Explicar ao paciente Que será feita a mudança de decúbito; } \\
\text { 10. Manter os lençóis limpos, secos e bem esticados; } \\
\text { 11. Monitorar a função urinária; } \\
\text { 12. Monitorar a eliminação intestinal; } \\
\text { 13. Observar e registrar o aparecimento de edema e hiperemia nas proeminências ósseas; } \\
\text { 14. Proteger as proeminências ósseas com filme transparente adesivo não estéril; } \\
\text { 15. Oferecer apoio a áreas edemaciadas com coxins, Quando necessário; } \\
\text { 16. Posicionar o paciente levando em conta o alinhamento correto do corpo; } \\
\text { 17. Posicionar o paciente confortavelmente; } \\
\text { 18. Proteger área de apoio e pressão por meio do uso de colchão caixa de ovo; } \\
\text { 19. Proteger com coxins as proeminências ósseas; } \\
\text { 20. Trocar roupas de cama. }\end{array}$ \\
\hline 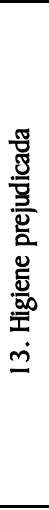 & $\begin{array}{l}\text { I. Auxiliar na escovação dos dentes e no enxágüe da boca, conforme a capacidade de autocuidado do paciente; } \\
\text { 2. Auxiliar no banho; } \\
\text { 3. Dar banho no leito; } \\
\text { 4. Encorajar o paciente/família para continuar executando a rotina de hi giene Quando retornar a casa; } \\
\text { 5. Ensinar técnica de escovação dos dentes; } \\
\text { 6. Estimular hábitos de higiene; } \\
\text { 7. Higienizar o paciente; } \\
\text { 8. Investigar as necessidades de aprendizagem do paciente; } \\
\text { 9. Orientar a lavagem dos cabelos, conforme a capacidade de autocuidado do paciente; } \\
\text { 10. Orientar a limpeza das unhas, conforme a capacidade de autocuidado do paciente; } \\
\text { 11. Orientar a troca de roupas após o banho, ou Quando necessário; } \\
\text { 12. Orientar o paciente/família a respeito da rotina de higiene no hospital; } \\
\text { 13. Orientar Quanto à necessidade de uma rotina diária de cuidado oral; } \\
\text { 14. Orientar sobre hábitos de higiene; } \\
\text { 15. Providenciar material de higiene. }\end{array}$ \\
\hline 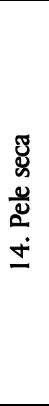 & $\begin{array}{l}\text { 1. Discutir o conhecimento do paciente sobre a sua necessidade de ingestão de líQuidos; } \\
\text { 2. Encorajar o paciente/família para continuar executando a rotina de cuidados com a pele, Quando retornar a casa; } \\
\text { 3. Estimular ingestão de líquidos; } \\
\text { 4. Evitar massagem sobre as saliências ósseas; } \\
\text { 5. Examinar a condição da pele, Quando adequado; } \\
\text { 6. Hidratar a pele; } \\
\text { 7. Investigar as necessidades de aprendizagem do paciente; } \\
\text { 8. Monitorar áreas ressecadas da pele; } \\
\text { 9. Orientar a evitar água Quente no banho; } \\
\text { 10. Orientar a usar sabão suave no banho; } \\
\text { 11. Orientar o uso de hidratante; } \\
\text { 12. Orientar paciente/família a respeito da rotina de cuidados com a pele. }\end{array}$ \\
\hline
\end{tabular}

\section{CONCLUSÕES}

O uso da CIPE ${ }^{\circledR}$ Versão 1.0, como uma terminologia de referência para esta pesquisa, permitiu o mapeamento cruzado dos termos identificados na Clínica Médica com os termos do Modelo de Sete Eixos, uma vez que a mesma foi desenvolvida para harmonizar os 


\begin{tabular}{|c|c|}
\hline \multicolumn{2}{|r|}{ NECESSIDADES PSICOBIOLÓGICAS } \\
\hline $\mathrm{DE}$ & Intervenção de Enfermagem \\
\hline 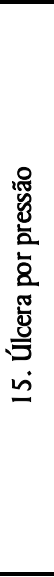 & $\begin{array}{l}\text { I. Aplicar curativo de ferida primário e secundário; } \\
\text { 2. Assegurar uma ingestão nutricional adequada; } \\
\text { 3. Avaliar a ferida a cada troca de curativo; } \\
\text { 4. Descrever as características da úlcera, incluindo o tamanho, profundidade, o estágio (I-IV), a localização, a granulação ou o } \\
\text { tecido desvitalizado e a epitelização; } \\
\text { 5. Hidratar a pele; } \\
\text { 6. Lavar a ferida com soro morno; } \\
\text { 7. Limpar a pele em torno da úlcera com sabão suave e água; } \\
\text { 8. Manter a úlcera úmida para auxiliar a cicatrização; } \\
\text { 9. Manter pele limpa e seca; } \\
\text { 10. Monitorar a cor, a temperatura, o edema, a umidade e a aparência da pele circunvizinha; } \\
\text { 11. Monitorar o estado nutricional; } \\
\text { 12. Monitorar sinais e sintomas de infecção da úlcera; } \\
\text { 13. Orientar a família/cuidador a realizar os procedimentos de cuidado com a ferida; } \\
\text { 14. Posicionar o paciente a cada } 2 \text { horas de modo a evitar pressão prolongada; } \\
\text { 15. Trocar curativo Quando adeQuado; } \\
\text { 16. Utilizar colchões e cama apropriados, Quando adeQuado. }\end{array}$ \\
\hline $\begin{array}{l}\frac{0}{0} \\
\frac{D}{2} \\
\underline{2} \\
\underline{0}\end{array}$ & $\begin{array}{l}\text { 1. Aplicar compressas frias para aliviar a irritação; } \\
\text { 2. Aplicar cremes e loções, Quando adeQuado; } \\
\text { 3. Aplicar medicação tópica após o banho; } \\
\text { 4. Determinar a causa do prurido; } \\
\text { 5. Ensinar uso da medicação via tópica; } \\
\text { 6. Examinar a integridade da pele; } \\
\text { 7. Manter as unhas do paciente limpas e cortadas; } \\
\text { 8. Orientar o paciente a usar a palma da mão para coçar a pele; } \\
\text { 9. Orientar o paciente a banhar-se em água morna e a dar tapinhas leves com a toalha ao secar a pele; } \\
\text { I0. Orientar o paciente a cortar as unhas curtas; } \\
\text { I1. Orientar o paciente a evitar sabões e óleos de banho perfumados; } \\
\text { 12. Orientar o paciente a não vestir roupas apertadas, tecidos de lã e sintéticos; } \\
\text { I3. Orientar o paciente a tomar banho antes de dormir para aliviar o prurido; } \\
\text { 14. Orientar Quanto ao autocuidado com a pele; } \\
\text { 15. Trocar roupas de cama diariamente. }\end{array}$ \\
\hline 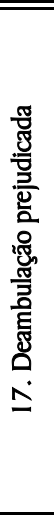 & $\begin{array}{l}\text { 1. Ajudar na deambulação; } \\
\text { 2. Ajudar o paciente a andar a intervalos regulares; } \\
\text { 3. Ajudar o paciente a ficar de pé e a percorrer uma distância específica; } \\
\text { 4. Auxiliar o paciente a sentar-se à beira da cama para facilitar os ajustes posturais; } \\
\text { 5. Auxiliar o paciente a transferir-se, conforme a necessidade; } \\
\text { 6. Auxiliar o paciente a usar calçado Que facilite o andar e previna lesões; } \\
\text { 7. Avaliar o progresso do paciente na sua deambulação; } \\
\text { 8. Encorajar a deambulação independente, dentro de limites seguros; } \\
\text { 9. Encorajar a sentar-se à beira do leito ou em cadeira, conforme a tolerância; } \\
\text { 10. Encorajar o paciente a permanecer de pé de acordo com sua vontade; } \\
\text { 11. Estimular a deambulação; } \\
\text { 12. Oferecer um ambiente seguro para a prática da deambulação; } \\
\text { 13. Orientar paciente/cuidador sobre técnicas de transferência e deambulação seguras; } \\
\text { 14. Providenciar cadeira de rodas para a deambulação se o paciente está inseguro; } \\
\text { 15. Vestir o paciente com roupas confortáveis. }\end{array}$ \\
\hline 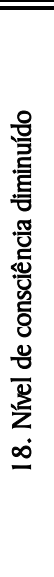 & $\begin{array}{l}\text { 1. } \\
\text { 2. Avaliar o nível de consciência; } \\
\text { 3. Daliar perfusão tissular periférica; } \\
\text { 4. Estimular a memória, repetindo o último pensamento Que o paciente expressou; } \\
\text { 5. Evitar frustrar o paciente com perguntas sobre orientação Que ele não possa responder; } \\
\text { 6. Evitar situações desconhecidas, Quando possível; } \\
\text { 7. Informar o paciente sobre pessoas, tempo e local, na medida das necessidades; } \\
\text { 8. Manter acesso intravenoso pérvio; } \\
\text { 9. Monitorar mudanças no nível de consciência do paciente; } \\
\text { 10. Monitorar eliminação urinária; } \\
\text { 11. Monitorar sinais vitais; } \\
\text { 12. Observar coloração da pele e temperatura; } \\
\text { 13. Oferecer um ambiente físico e uma rotina diária consistente; } \\
\text { 14. Favorecer repouso/sono adeQuados; } \\
\text { 15. Tratar sempre o paciente pelo nome ao iniciar a interação; } \\
\text { 16. Usar gestos/objetos para aumentar a compreensão das comunicações verbais; } \\
\text { 17. }\end{array}$ \\
\hline
\end{tabular}




\begin{tabular}{|c|c|}
\hline \multicolumn{2}{|r|}{ NECESSIDADES PSICOBIOLÓGICAS } \\
\hline $\mathrm{DE}$ & Intervenção de Enfermagem \\
\hline 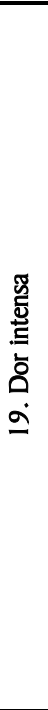 & $\begin{array}{l}\text { 1. Ajudar o paciente a ficar em posições confortáveis; } \\
\text { 2. Aplicar compressa fria; } \\
\text { 3. Aplicar compressa Quente; } \\
\text { 4. Avaliar a dor Quanto à localização, freqüência e duração; } \\
\text { 5. Avaliar a eficácia das medidas de controle da dor por meio de um levantamento constante da experiência de dor; } \\
\text { 6. Controlar os fatores ambientais capazes de influenciar a resposta do paciente ao desconforto (p.ex.: temperatura ambiente, } \\
\text { iluminação, ruído); } \\
\text { 7. Descrever as características da dor, incluindo local, o início, duração, freqüência, Qualidade, intensidade e os fatores } \\
\text { 8. Encipitantes; } \\
\text { 9. Explicar as causas da dor; } \\
\text { 10. Investigar os fatores Que aumentam a dor; } \\
\text { 11. Manter repouso no leito; } \\
\text { 12. Monitorar a dor após administração de medicamento; } \\
\text { 13. Monitorar a satisfação do paciente com o controle da dor, a intervalos específicos; } \\
\text { 14. Observar indicadores não-verbais de desconforto; } \\
\text { 15. Oferecer ambiente calmo e agradável; } \\
\text { 16. Orientar o paciente Quanto à necessidade de repouso durante a dor; } \\
\text { 17. Reduzir ou eliminar os fatores Que precipitem ou aumentem a experiência de dor (p.ex.: medo, fadiga, monotonia e falta } \\
\text { 18. Se informação); } \\
\text { Selecionar e implementar medidas de alívio da dor, Quando necessário. }\end{array}$ \\
\hline 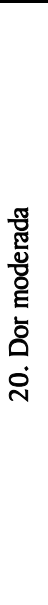 & $\begin{array}{l}\text { 1. Avaliar a dor Quanto à localização, freqüência e duração; } \\
\text { 2. Avaliar a eficácia das medidas de controle da dor por meio de um levantamento constante da experiência de dor; } \\
\text { 3. Controlar os fatores ambientais capazes de influenciar a resposta do paciente ao desconforto (p.ex.: temperatura } \\
\text { ambiente, iluminação, ruído); } \\
\text { 4. Descrever as características da dor, incluindo local, o início, duração, freqüência, Qualidade, intensidade e os atores } \\
\text { precipitantes; } \\
\text { 5. Encorajar o paciente a discutir sua experiência de dor, Quando adequado; } \\
\text { 6. Encorajar o paciente a monitorar a própria dor e a interferir adequadamente; } \\
\text { 7. Ensinar o uso de técnicas não farmacológicas (relaxamento, imagem orientada, musicoterapia, diversão, aplicação de } \\
\text { compressas frias/Quentes, aplicação de massagem) antes, após e se possível durante a atividade dolorosa; } \\
\text { 8. Incorporar a família na modalidade de alívio da dor, se possível; } \\
\text { 9. Monitorar a satisfação do paciente com o controle da dor, a intervalos específicos; } \\
\text { 10. Observar indicadores não-verbais de desconforto; } \\
\text { 11. Oferecer informações sobre a dor, suas causas, tempo de duração, Quando apropriado; } \\
\text { 12. Reduzir ou eliminar os fatores Que precipitem ou aumentem a experiência de dor (p.ex.: medo, fadiga, monotonia e falta } \\
\text { 13. Ue informação); } \\
\text { 14. Verificar o nível de desconforto com o paciente. }\end{array}$ \\
\hline 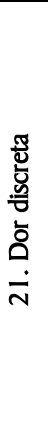 & $\begin{array}{l}\text { 1. Avaliar a dor Quanto a localização, freqüência e duração; } \\
\text { 2. Avaliar a eficácia das medidas de controle da dor por meio de um levantamento constante da experiência de dor; } \\
\text { 3. Controlar os fatores ambientais capazes de influenciar a resposta do paciente ao desconforto (p.ex.: temperatura } \\
\text { ambiente, iluminação, ruído); } \\
\text { 4. Descrever as características da dor, incluindo local, o início, duração, freeüência, Qualidade, intensidade e os fatores } \\
\text { precipitantes; } \\
\text { 5. Ensinar o uso de técnicas não farmacológicas (relaxamento, imagem orientada, musicoterapia, diversão, aplicação de } \\
\text { compressas frias/Quentes, aplicação de massagem) antes, após e se possível durante a atividade dolorosa; } \\
\text { 6. Incorporar a família na modalidade de alívio da dor, se possível; } \\
\text { 7. Monitorar a satisfação do paciente com o controle da dor, a intervalos específicos; } \\
\text { 8. Oferecer informações sobre a dor, suas causas, tempo de duração, Quando apropriado; } \\
\text { 9. Favorecer o repouso/sono adeQuado para facilitar o alívio da dor; } \\
\text { 10. Verificar o nível de desconforto com o paciente. }\end{array}$ \\
\hline
\end{tabular}

vocabulários existentes, desenvolver vocabulários novos, e documentar sistematicamente a prática profissional, usando diagnósticos, resultados e intervenções de enfermagem, normalizados, constituindo-se numa ferramenta de informação para descrever a prática de enfermagem e fornecer dados representativos desta prática em sistemas abrangentes de informação à saúde.

Acredita-se Que a inserção desta nomenclatura na Clínica Médica do HULW/UFPB oportunizará ao serviço acesso aos dados, capazes de gerar informação e conhecimento para melhoraria na Qualidade da assistência, da gestão, do ensino e da pesQuisa. Reconhece-se Que os termos, as afirmações teóricas, os diagnósticos e as intervenções de enfermagem podem ser passíveis de inclusão, revisão, modificação ou exclusão, pelo fato de um sistema de classificação ser considerado um processo em contínuo desenvolvimento. Isto faz com Que este estudo não tenha o seu conteúdo dado como terminado.

Espera-se Que essas afirmativas poderão fazer parte de um catálogo CIPE ${ }^{\circledR}$ de caráter mais geral, contendo as afirmativas de 


\begin{tabular}{|c|c|}
\hline \multicolumn{2}{|r|}{ NECESSIDADES PSICOSSOCIAIS } \\
\hline $\mathrm{DE}$ & Intervenção de Enfermagem \\
\hline$\frac{\mathbb{Z}}{\frac{\pi}{0}}$ & $\begin{array}{l}\text { 1. Ajudar o paciente a identificar as situações precipitantes de ansiedade; } \\
\text { 2. Apoiar o uso de mecanismos de defesa apropriados; } \\
\text { 3. Controlar os estímulos, conforme apropriado às necessidades do paciente; } \\
\text { 4. Estimular a verbalização de sentimentos e medo; } \\
\text { 5. Estimular comunicação com o paciente; } \\
\text { 6. Explicar expectativas de estado do comportamento do paciente; } \\
\text { 7. Identificar Quando o nível de ansiedade se modifica; } \\
\text { 8. Monitorar o estado emocional do paciente; } \\
\text { 9. Oferecer ambiente calmo; } \\
\text { 10. Oferecer apoio psicológico; } \\
\text { 11. Oferecer atividades de diversão voltadas à redução da tensão; } \\
\text { 12. Oferecer informações sobre diagnóstico, tratamento e prognóstico; } \\
\text { 13. Orientar paciente Quanto ao uso de técnicas de relaxamento; } \\
\text { 14. Ouvir atentamente; } \\
\text { 15. Permanecer com o paciente para promover segurança e reduzir o medo; } \\
\text { 16. Promover adaptação do paciente ao ambiente hospitalar; } \\
\text { 17. Proporcionar bem-estar; } \\
\text { 18. Reforçar comportamentos, conforme apropriado; } \\
\text { 19. Usar uma abordagem calma e segura. }\end{array}$ \\
\hline
\end{tabular}

diagnóstico/resultados e intervenções de enfermagem relacionadas às necessidades comuns a todas as pessoas internadas na Clínica Médica ou de catálogos CIPE ${ }^{\circledR}$ para grupos específicos de clientes de especialidades atendidas na referida clínica. Espera-se também
Que o uso desta nomenclatura, enQuanto instrumento tecnológico de enfermagem permita o emprego do raciocínio clínico, individualização da assistência e, conseQüentemente, impulsione os enfermeiros a Questionar e modificar sua atuação profissional.

\section{REFERÊNCIAS}

1. Marin HF. Vocabulário: recurso para construção de base de dados de enfermagem. Acta Paul Enferm 2000; I3(1): 86-9.

2. Santos RS, Paula AFA. O enfermeiro e sua percepção sobre o sistema manual de registro no prontuário. Rev Latino-am Enfermagem 2003; II(1): 80-7.

3. Internacional Council of Nurses. International Classification for nursing Practice - ICNP ${ }^{\circledR}$ Verson I. Geneva: ICN; 2005.

4. International Standards Organization. ISO 18.104. Health informatics - integration of a reference terminology model for nursing. Geneva: International Standards for Organization; 2003.

5. Ministério da Saúde (BR). Conselho Nacional de Saúde. Comissão Nacional de Ética em Pesquisa - CONEP. Resolução
196/96: dispõe sobre pesquisa envolvendo seres humanos. Brasília: Ministério da Saúde; 1996.

6. Furtado LG, Nóbrega MML. Construção de Banco de Termos identificados em registros de enfermagem utilizando a CIPE ${ }^{\circledR}$. Revista Eletrôn Enferm 2007; 9(3): 630-55.

7. Ferreira, ABH. Dicionário Aurélio eletrônico século XXI. Versão 5.0. São Paulo: Positivo; 2004.

8. Pavel S, Nolet D. Manual de terminologia. Ottawa: Public Works and Government Services; 2003.

9. Conselho Internacional de Enfermagem. Classificação Internacional para a Prática de Enfermagem - Versão 1.0. São Paulo: Algol; 2007. 